\title{
The Effect of Orthographic Structure on Word Recognition in a Visual Search Task
}

\author{
Keith E. Stanovich \\ Oakland University \\ RICHARD F. WEST \\ James Madison University
}

AND

Denise Pollak

University of Michigan

\begin{abstract}
The effect of the orthographic structure of the stimulus field on the visual search performance of third graders (8-8 years), sixth graders (11-7 years) and adults was investigated in three experiments. In Experiment 1, where the predesignated target was one word, subjects of all ages searched equally fast through fields consisting of words, pseudowords, and nonwords. In contrast, subjects of all ages displayed effects of orthographic structure when searching for instances of a semantic category (Experiment 2) or for three words (Experiment 3). Subjects searched faster through nonwords than through pseudowords and faster through pseudowords than through words. The use of orthographic structure to facilitate search did not increase with age, suggesting that children of the youngest age group were already making maximal use of intraword redundancy.
\end{abstract}

The visual search task popularized by Neisser and colleagues (Neisser, 1963; Neisser \& Beller, 1965; Neisser, Novick, \& Lazar, 1963) has become a major diagnostic tool of researchers investigating human information processing. The general paradigm involves having the subject scan down a vertical list of items and indicate when he has found a predesignated target. The latency in locating the target has been the primary dependent variable in this research. The number of targets and the makeup of the items in the list have been important independent variables.

In recent years, several investigators have employed visual search tasks in order to tap various components of the reading process. Krueger (1970) found that adults could search for a letter faster through lists composed of

Requests for reprints should be sent to Keith E. Stanovich, Department of Psychology, Oakland University, Rochester, Michigan 48063. 
words rather than nonwords. Letter search was also faster through words than through pseudowords which were equated in trigram frequency. Finally, subjects were faster in searching through pseudowords than through nonwords that did not reflect the sequential constraints of English.

Krueger, Keen, and Rublevich (1974) conducted a developmental investigation of the effect of orthographic structure on letter search performance. Adults and fourth-grade children displayed faster letter search rates for word lists than for nonword lists. Search through pseudowords was faster than search through nonwords that did not reflect the sequential constraints of English. The magnitude of these effects, as indicated by the relative reduction in search times, was the same for both age groups. In fact, the absolute reduction was actually greater for the children. These results indicate that fourth-grade children can make use of intraword redundancy to aid performance. Indeed, their use of this type of redundancy seems to have already reached the level attained by fluent adult readers. Letter search paradigms have been employed to investigate other types of intraword redundancy. Mason (1975) used such a task in an attempt to determine whether good and poor readers differed in their use of redundancy defined by single-letter positional frequency. This is a type of redundancy that arises because individual letters appear in different spatial positions of words with differing frequencies.

Interest in the effect of intraword redundancy has arisen because this variable plays a large role in many theories of word recognition and the reading process (e.g., Rumelhart \& Siple, 1974; Smith, 1971; Smith \& Spoehr, 1974). Unfortunately, there have been few developmental investigations of this important variable. The studies that have been reported have invariably used letter recognition (as opposed to words or some other unit of recognition), cither in the context of search tasks (e.g., Krueger, Keen, \& Rublevich, 1974) or in the context of tachistoscopic tasks (e.g., Lott \& Smith, 1970). There are two reasons why the emphasis on letter search may be unwarranted. Mason (1975) states that the theoretical rationale for the use of letter detection is provided by research showing that the perceptual unit in the recognition of tachistoscopically presented words is the individual letter (Massaro, 1973; Thompson \& Massaro, 1973). Although a critique of the Massaro (1973) and Thompson and Massaro (1973) studies is beyond the scope of this paper, it should be noted that alternative conceptualizations of their results have been published (Estes, 1975; Johnson \& McClelland, 1974, Smith \& Spoehr, 1974; Spector \& Purcell, 1977). Suffice it to say that the size of the perceptual units involved in word recognition is still an open question (see Krueger, 1975; Smith \& Spoehr, 1974; Spector \& Purcell, 1977). Sole reliance on letter search in developmental studies of orthographic redundancy is not justified by work on the perceptual unit problem.

The second reason why the emphasis on letter search may not be justified is that much research in cognitive psychology supports the notion that the 
level of processing at which a subject is set to operate can determine the effect of many experimental variables. For example, Shulman (1970) has shown that subjects can store semantic information in short-term memory if given the proper set. In addition, the amount of facilitation due to semantic context in lexical decision tasks is affected by the level of coding induced by the structure of the nonword strings (Shulman \& Davison, 1977). Finally, Ball, Wood, and Smith (1975) have shown that in visual search tasks, the level of the unit for which the subject is searching partially determines the relative efficiency of visual, acoustic, and semantic search.

The implication of the preceding discussion is that it cannot be assumed that the effect of a variable on search performance will be the same when subjects are operating at a different processing level (i.e., searching for different size units or for examples of a category). In addition, the issue of ecological validity should also be considered. With the exception of the beginner, most readers are operating at either semantic integration or word recognition levels, rather than at the level of individual letter recognition. Indeed, it is probably the case (see Smith, 1971) that text must be processed at least at the level of word recognition for any meaning to be extracted.

The purpose of the present paper is to examine the development of the use of orthographic structure when subjects are performing the visual search task at the word level or higher. Previous developmental studies have employed words as targets (e.g., Fisher \& Lefton, 1976; Lefton \& Fisher, 1976; Leslie \& Calfee, 1971), but none have looked at orthographic structure effects. The logic of the experiments reported here is similar to that used by Karlin and Bower (1976) in their studies of adults' use of semantic categories when searching for words. That is, a target was defined and maintained throughout a series of trials. Trials differed with respect to the field through which the subject searched (in the case of the present studies, words, pseudowords, and nonwords). If search time differed across the various field conditions, then the subject was assumed to be sensitive to the features which differentiated the field types.

\section{EXPERIMENT 1}

In Experiment 1, subjects of three ages searched for one predesignated word through lists consisting of words, pseudowords, and nonwords. Pseudowords were so-called because they were constructed to approximate the local sequential constraints of real words. Strings constructed in this way are usually easily pronounceable. The nonword strings were constructed so as not to reflect the sequential constraints of English, and they were invariably unpronounceable.

\section{Method}

Subjects. Seventy-two subjects participated in the experiment, 48 children and 24 adults. The younger children were 24 third graders with a mean 
age of 8 years, 8 months (range $8-1$ to 9-4). There were 8 males and 16 females in this group. The older children were 24 sixth graders with a mean age of 11 years, 7 months (range 11-1 to 12-3). There were 14 males and 10 females in this group. The children were tested late in the academic year and were from a school whose students were, as a whole, above the national average in reading ability. Twenty-four undergraduate college students (13 males and 11 females) were recruited through an introductory psychology subject pool for participation in the study.

Materials. The stimulus materials were lists consisting of letter strings. Each list was typed on a separate sheet $(21 \times 28 \mathrm{~cm})$ in IBM Courier 72, 10 pitch. All letters were lower casc. Each sheet contained four, 20-line columns, and each line contained five letters. Of the total of 80 strings, 20 were occurrences of the target, and the remaining strings constituted the field. Targets were randomly placed in the list with the constraint that a target occurred once in every four lines.

There were three types of fields: words, pseudowords, and nonwords. The word field consisted of high-frequency, five-letter words from the Kučera and Francis (1967) count. The pseudoword field strings were constructed so as to approximate the words in the sequential constraints of their component letter pairs. This was accomplished by using the tables of digram frequency counts for various wordlength and letter-position combinations compiled by Mayzner and Tresselt (1965). These tables are based on a sample of 20,000 words. A digram frequency is the frequency with which a particular letter pair occurs at a certain location within a word of a particular size. Thus, one summary measure of the sequential constraints in a letter string is the sum of its digram frequencies. The mean summed digram frequency of the 60 words was 267 . The pseudowords were constructed by making nonword anagrams of the words that had approximately the same summed digram frequency. This resulted in a set of 60 pseudowords that had a mean summed digram frequency of 278, approximately equal to that of the word field. In addition, almost all of the pseudowords were pronounceable (e.g., fornt). The nonwords were constructed by making anagrams of the words that were low in summed digram frequency. The mean summed digram frequency of the nonword field was one, and almost none of them was pronounceable (e.g., rtfno). A hand-held stop watch was used to measure the search duration. Latencies were measured to the nearest $0.1 \mathrm{sec}$.

Procedure. Subjects were individually tested in a session that lasted approximately $10 \mathrm{~min}$. Search sheets were shown to the subjects, who were told to scan through the lists and cancel (i.e., "put a small line through the word") every occurrence of a designated target word. Subjects were instructed to work as rapidly as they could without missing any of the targets. A small card $(8 \times 10 \mathrm{~cm})$ with the target word typed on it was shown to the subject before each trial. Beginning with the left- 
TABLE 1

Mean Search Times (in Sec) and Mean Number of Errors FOR THE THREE Field CONDITIONS

\begin{tabular}{|c|c|c|c|c|c|c|}
\hline \multirow[b]{2}{*}{ Group } & \multicolumn{2}{|c|}{ Words } & \multicolumn{2}{|c|}{ Pseudowords } & \multicolumn{2}{|c|}{ Nonwords } \\
\hline & Search time & Errors & Search time & Errors & Search time & Errors \\
\hline \multicolumn{7}{|c|}{ Experiment 1} \\
\hline Third grade & 41.5 & .54 & 42.1 & .46 & 41.6 & .96 \\
\hline Sixth grade & 30.7 & .38 & 31.6 & .71 & 30.8 & .58 \\
\hline Adults & 23.0 & .83 & 23.3 & 1.25 & 22.9 & .88 \\
\hline \multicolumn{7}{|c|}{ Experiment 2} \\
\hline Third grade & 58.9 & .83 & 52.6 & .79 & 50.1 & .79 \\
\hline Sixth grade & 40.3 & .29 & 38.7 & .38 & 34.2 & .42 \\
\hline Adults & 29.1 & .29 & 26.7 & .21 & 24.0 & .29 \\
\hline \multicolumn{7}{|c|}{ Experiment 3} \\
\hline Third grade & 49.8 & .29 & 48.4 & .42 & 43.9 & .21 \\
\hline Sixth grade & 38.6 & .25 & 35.4 & .25 & 34.1 & .29 \\
\hline Adults & 28.9 & .54 & 26.1 & .33 & 25.4 & .29 \\
\hline
\end{tabular}

hand column, search progressed from the top of each column downward. Timing began when the experimenter uncovered a stimulus sheet and said "Go." Timing ended when the subject finished searching through the bottom line of the right-hand column and said "Done."

Subjects were given two practice sheets on which they had to search for the target word "small." The field of practice sheets was a mixture of all three item types (words, pseudowords, and nonwords). After the two practice sheets, subjects searched through three different sheets for the target word "table." These three sheets were the three conditions of field type (words, pseudowords, and nonwords). The order of conditions was completely counterbalanced across subjects. If a subject missed a target word, he was not corrected while he was searching. This was counted as an error.

\section{Results and Discussion}

Since there were no sex differences on any of the performance measures, data from males and females will be pooled in the analysis that follows. The mean search times and mean number of errors for each age group and each condition are presented in Table 1. An analysis of variance on the search times was performed with age as a between subjects factor and field condition as a within subjects factor. This 
analysis indicated that the effect of age was significant at the .001 level $(F(2,69)=84.79, M S E=74.4)$. However, neither the condition effect $(F(2,138)=2.57, M S E=3.3)$ nor the age by condition interaction $(F(4,138)=.21, M S E=3.3)$ was significant. An analysis of covariance carried out on the search times, with number of errors as a covariate, produced results virtually identical to those obtained from the analysis of variance.

The results of the statistical analysis indicated that the makeup of the field did not affect the search times of any of the age groups. It appears that subjects are not sensitive to orthographic structure when they are operating at the level of word recognition. However, this unexpected conclusion is subject to one crucial caveat. It is possible that the procedure of having subjects search for one word which did not change over trials enabled their use of search strategies involving levels of processing more elementary than that of word recognition. For example, subjects might have looked for the physical features defining the word's shape or simply for the first one or two letters. Karlin and Bower (1976) suggested such an explanation for the results of their first experiment, where adults searching for one word showed no effect of semantic category of the field. These investigators did find such an effect when the subjects had to search for more than one target word. In Experiment 2, the effect of orthographic structure in a search task is tested under conditions where the subjects cannot discriminate the target on the basis of simple physical features. Subjects searched through the same three field types for instances of a predesignated category.

\section{EXPERIMENT 2}

\section{Method}

Subjects were the same as in Experiment 1. The three field conditions and all other aspects of the procedure were also the same as in Experiment 1 , except that the subjects were asked to search for members of the category "clothes." Subjects were not informed what specific words would be used as instances of the category. The target words were shoes, dress, glove, shirt, and pants. These words were substituted in the search lists in the locations where "table" had appeared in Experiment 1. Each target word appeared equally often.

\section{Results and Discussion}

Since there were no sex differences on any of the performance measures, data from males and females will be pooled in the analyses that follow. The mean search times and mean number of errors for each age group and each condition are presented in Table 1. An analysis of variance on the search times was performed with age as a between sub- 
jects factor and field condition as a within subjects factor. This analysis indicated that the effects of age $(F(2,69)=79.33, M S E=170.5)$ and field condition $(F(2,138)=20.64, M S E=38.8)$ were significant at the .001 level. The age by condition interaction was not significant $(F(4,138)$ $=1.18, M S E=38.8$ ). An analysis of covariance carried out on the search times, with number of errors as a covariate, produced results virtually identical to those obtained from the analysis of variance.

For all three age groups the mean search times were ordered as expected. Subjects searched faster through nonwords than through pseudowords and faster through pseudowords than through words. Planned orthogonal contrasts indicated that for all three age groups search times were longer for the word condition than for the pseudoword and nonword conditions averaged $(p<.001$ for third graders, $p<.05$ for sixth graders and adults). In addition, sixth graders searched faster through nonwords than through pseudowords $(p<.05)$.

It appears that when searching for instances of a semantic category, subjects of all three ages made use of the orthographic characteristics of the field to aid their search performance. Search was fastest through nonwords, presumably because their orthographic structure allows them to be easily classified as nontargets. Search was next fastest through pseudowords. These stimulus strings can be more easily classified as nontargets either because they have no meaning or because orthographic characteristics more global than simple digram frequency distinguish them from words. Although Scheffé post hoc comparisons indicated that not all the individual comparisons were statistically significant, it is the case that all age groups showed the aforementioned ordering of conditions. In addition, post hoc tests did indicate that search times for the word condition exceeded that for the nonword condition in all three age groups. Furthermore, there was no indication that the use of orthographic structure increases across the ages studied here. Specifically, there was no hint of an age by condition interaction.

\section{EXPERIMENT 3}

Experiment 2 demonstrated that orthographic structure does facilitate search when subjects are operating at the semantic level. This contrasts with the results obtained when subjects are searching for a single word. Experiment 1 showed that orthographic structure effects are absent in such a task, presumably because the subjects do not have to operate at the level of word recognition to perform efficiently (see Karlin \& Bower, 1976). However, it is important to know whether the results of Experiment 2 are dependent on the semantic nature of the task or whether they might be obtained when the subjects operate at the level of word recognition. Thus, in Experiment 3, subjects of three ages searched for three predesignated words. This type of task does not require them to extract 
semantic information, but at the same time it renders inefficient search strategies based on first letters or simple physical features (i.e., the type of strategies that are possible when only one word is the target). Karlin and Bower (1976) have shown that search field effects which are quite large in a multiple-word search task, can be totally absent when the task is single-word search.

\section{Method}

Subjects were the same as in Experiments 1 and 2. The three field conditions and all other aspects of the procedure were also the same as in Experiments 1 and 2, except that the subjects were asked to search for the three words "party," "house," and "world." The three words were randomly inserted in the search lists at the same target locations that were used in Experiments 1 and 2. The target word "house" appeared seven times, "world" appeared seven times, and "party" appeared six times. A small card $(8 \times 10 \mathrm{~cm})$ with the appropriate target words typed on it was shown to the subject before each trial.

\section{Results}

Since there were no sex differences on any of the performance measures, data from males and females will be pooled in the analyses that follow. The mean search times and mean number of errors for each age group and each condition are presented in Table 1. An analysis of variance on the search times was performed with age as a between subjects factor and field condition as a within subjects factor. This analysis indicated that the effects of age $(F(2,69)=99.14, M S E=76.7)$ and field condition $(F(2,138)=42.65, M S E=9.2)$ were significant at the .001 level. The age by condition interaction was significant $(F(4,138)=2.83, p<.05, M S E$ $=9.2$ ). An analysis of covariance carried out on the search times, with number of errors as covariate, produced results virtually identical to those obtained from the analysis of variance.

As in Experiment 2, the mean search times of all three age groups showed the expected ordering. Subjects searched faster through nonwords than through pseudowords, and faster through pseudowords than through words. Planned orthogonal contrasts indicated that for all three age groups search times were longer for the word condition than for the pseudoword and nonword conditions averaged $(p<.001)$ for all three groups. In addition, third graders searched faster through nonwords than through pseudowords $(p<.001)$. Scheffé post hoc comparisons indicated that the only interaction to approach significance was the pseudoword-nonword difference across third graders and adults $(p<.06)$.

\section{GENERAL DISCUSSION}

Experiment 3 replicated the finding of Experiment 2, namely, that subjects of all three ages can use orthographic structure to facilitate search 
performance. Further, the facilitative effect can be obtained either when the subject is searching for instances of a semantic category or when he is looking for a small number of predesignated words. The lack of a field effect in Experiment 1 seems to be because the subjects are not searching for targets at the word level. Thus, the results reported here dovetail with those of Karlin and Bower (1976) who found field effects only when subjects searched for more than one target word.

Experiments 2 and 3 found no evidence for an increasing use of orthographic structure with age. There was no condition by age interaction in Experiment 2. Although this interaction was marginally significant in Experiment 3, it was in a direction opposite from what might be expected. Children displayed slightly more of an orthographic structure effect than did adults. Although the authors prefer a tentative approach to such a statistically marginal interaction, one might speculate that the word recognition process of adults has become so automatized (in the sense of LaBerge \& Samuels, 1974) that it displays less of a dependence on the contextual field than that of children. Nevertheless, the one clear conclusion is that after third grade there seems to be no increase in the use of orthographic structure.

\section{REFERENCES}

Ball, F., Wood, C., \& Smith, E. E. When are semantic targets detected faster than visual or acoustic ones? Perception and Psychophysics, 1975, 17, 1-8.

Estes, W. K. The locus of inferential and perceptual processes in letter identification. Journal of Experimental Psychology: General, 1975, 104, 122-145.

Fisher, D. F., \& Lefton, L. A. Peripheral information extraction: A developmental examination of reading processes. Journal of Experimental Child Psychology, 1976 , 21, 77-93.

Johnston, J. C., \& McClelland, J. L. Perception of letters in words: Seek not and ye shall find. Science, 1974, 184, 1192-1193.

Karlin, M. B., \& Bower, G. H. Semantic category effects in visual word search. Perception and Psychophysics, 1976, 19, 417-424.

Krueger, L. E. Search time in a redundant visual display. Journal of Experimental Psychology, 1970, 83, 391-399.

Krueger, L. E. Familiarity effects in visual information processing. Psychological Bulletin, 1975, 82, 949-974.

Krueger, L. E., Keen, R. H., \& Rublevich, B. Letter search through words and nonwords by adults and fourth-grade children. Journal of Experimental Psychology, 1974, 102, 845-849.

Kučera, H., \& Francis, W. N. Computational analysis of present-day American English. Providence, RI: Brown University Press, 1967.

LaBerge, D., \& Samuels, S. J. Toward a theory of automatic information processing in reading. Cognitive Psychology, 1974, 6, 293-323.

Lefton, L. A., \& Fisher, D. F. Information extraction during visual search: A developmental progression. Journal of Experimental Child Psychology, 1976, 22, 346-361.

Leslie, R., \& Calfee, R. C. Visual search through word lists as a function of grade level, reading ability, and target repetition. Perception and Psychophysics, 1971, 10, $169-171$. 
Lott, D., \& Smith, K. Knowledge of intraword redundancy by beginning readers. Psychonomic Science, 1970, 19, 343-344.

Mason, M. Reading ability and letter search time: Effects of orthographic structure defined by single-letter positional frequency. Journal of Experimental Psychology: General, $1975,104,146-166$.

Massaro, D. W. Pcrception of letters, words, and nonwords. Journal of Experimental Psychology, 1973, 100, 349-353.

Mayzner, M. S., \& Tresselt, M. E. Tables of single-letter and diagram frequency counts for various word-length and letter-position combinations. Psychonomic Monograph Supplements, 1965, 1 (2).

Neisser, U. Decision time without reaction time: Experiments in visual scanning. American Journal of Psychology, 1963, 76, 376-385.

Neisser, U., \& Beller, H. K. Searching through word lists. British Journal of Psychology, $1965,56,349-358$.

Neisser, U., Novick, R., \& Lazar, R. Searching for ten targets simultaneously. Perceptual and Motor Skills, 1963, 17, 955-961.

Rumelhart, D. E., \& Siple, P. Process of recognizing tachistoscopically presented words. Psychological Review, 1974, 81, 99-118.

Shulman, H. G. Encoding and retention of semantic and phonemic information in shortterm memory. Journal of Verbal Learning and Verbal Behavior, 1970, 9, 499-508.

Shulman, H. G., \& Davison, T. C. B. Control properties of semantic coding in a lexical decision task. Journal of Verbal Learning and Verbal Behavior, 1977, 16, 91-98.

Smith, E. E., \& Spoehr, K. T. The perception of printed English: A theoretical perspective. In B. H. Kantowitz (Ed.), Human information processing: Tutorials in performance and cognition. Hillsdale, $\mathrm{N} \mathrm{J}$ : Erlbaum Associates, 1974.

Smith, F. Understanding reading. New York: Holt, Rinehart and Winston, 1971.

Spector, A., \& Purcell, D. G. The word superiority effect: A comparison between restricted and unrestricted alternative set. Perception and Psychophysics, 1977, 21, 323-328.

Thompson, M. C., \& Massaro, D. W. Visual information and redundancy in reading. Journal of Experimental Psychology, 1973, 98, 49-54.

RECEIVED: July 5, 1977; REVISED: September 16, 1977. 